\title{
Fósforo no crescimento inicial de mogno-africano
}

\author{
Matheus da Silva Araújo $\oplus^{1 *}$ Cleiton da Silva Oliveira $\circledast^{2}$ José Eduardo Dias Calixto Júnior $\circledast^{3}$ Vitor \\ Corrêa de Mattos Barretto $\oplus^{4}$ Fabricio Rodrigues $\circledast^{5}$
}

\author{
${ }^{1}$ Universidade de São Paulo, Escola Superior de Agricultura "Luiz de Queiroz", Av. Pádua Dias - Agronomia, CEP: 13418-900, Piracicaba, \\ SP, Brasil \\ ${ }^{2}$ Secretaria Estadual de Meio Ambiente e Desenvolvimento Sustentável de Minas Gerais, Fazenda Canavial, Caixa Postal 240, CEP: 38.700- \\ 000- Patos de Minas, MG, Brasil \\ ${ }^{3}$ Universidade de Brasília, Asa Norte, CEP: 70910-900, Brasília, DF, Brasil \\ ${ }^{4}$ Universidade Estadual Paulista "Júlio de Mesquita Filho", Faculdade de Ciências Agrárias e Tecnológicas - FCAT, Departamento de \\ Produção Vegetal, Câmpus de Dracena, CEP: 17900-000, Dracena, SP, Brasil. \\ ${ }^{5}$ Universidade Estadual de Goiás. Br 153 Quadra Área Km 99 Zona Rural, CEP:75132-903, Anápolis, GO, Brasil
}

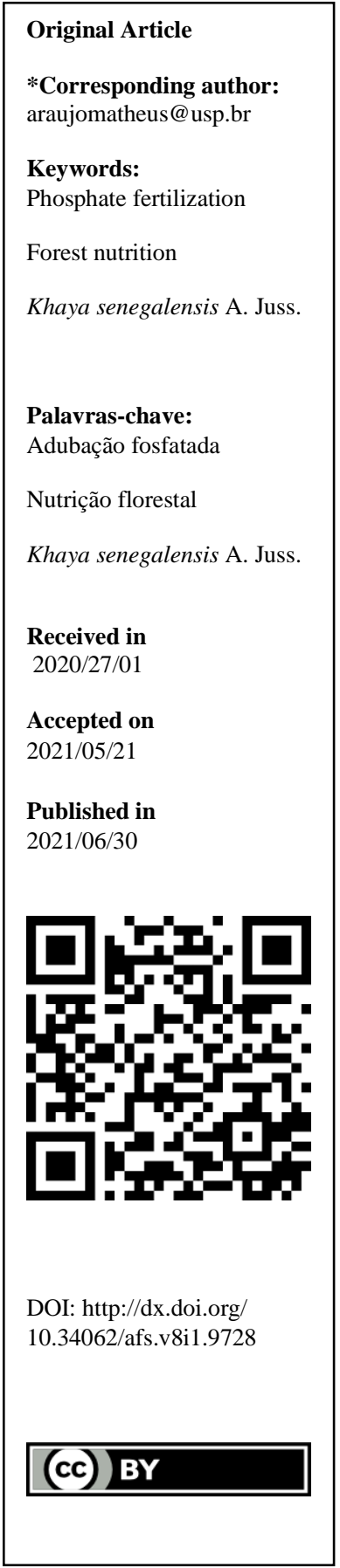

RESUMO: Objetivou-se avaliar o crescimento inicial de plantas mogno-africano (Khaya senegalensis A. Juss), adubadas com fósforo. O experimento foi realizado em casa de vegetação, em recipientes de plásticos com capacidade $\mathrm{de} 7 \mathrm{dm}^{3} \mathrm{e}$ utilizado como substrato amostras de solo identificado como Latossolo VermelhoAmarelo distrófico. O delineamento experimental utilizado foi inteiramente casualizado, com cinco tratamentos e seis repetições, totalizando 30 unidades experimentais. Os tratamentos constituíram-se de cinco doses de P: 0, 50, 100, 150 e $200 \mathrm{mg} \mathrm{dm}^{-3}$, sendo a fonte de adubação utilizada o superfosfato triplo. Aos 180 dias de transplantio, foram aferidos a altura da planta, o diâmetro do coleto, matéria seca de folhas, caule, raiz, e total, teor de P nas folhas e teor de P no solo. As doses de fósforo promoveram aumento no crescimento das plantas. O mognoafricano apresentou exigência em fósforo nas fases iniciais de crescimento para a condição edafoclimática estudada. A melhor resposta de crescimento em biomassa foi obtida com a dose estimada $175 \mathrm{mg} \mathrm{dm}^{-3}$ de P.

\section{Phosphorus in the early growth of African mahogany}

\begin{abstract}
The objective was to evaluate the initial growth of African mahogany plants (Khaya senegalensis A. Juss), fertilized with phosphorus. The experiment was carried out in a greenhouse, in plastic containers with a capacity of $7 \mathrm{dm}^{3}$ and used as substrate samples of soil identified as dystrophic Red-Yellow Latosol. The experimental design used was completely randomized, with five treatments and six repetitions, totaling 30 experimental units. The treatments consisted of five doses of P: 0, 50, 100, 150 and $200 \mathrm{mg} \mathrm{dm}^{-3}$, with the source of fertilization being triple superphosphate. At 180 days, plant height, stem diameter, leaf dry matter, stem, root, and total, $\mathrm{P}$ content in leaves and $\mathrm{P}$ content in soil were measured. The increasing doses of phosphorus promoted an increase in plant growth. African mahogany showed a requirement for phosphorus in the early stages of development for the studied edaphoclimatic condition. The best growth response was obtained with dose of $175 \mathrm{mg} \mathrm{dm}^{-3}$ of $\mathrm{P}$.
\end{abstract}


Introdução

Com o grande aumento da demanda de produtos e subprodutos florestais, e a crescente procura por novas espécies com potencial econômico, o setor florestal brasileiro vem sendo desenvolvido consideravelmente, tornando-se um segmento de grande importância na cadeia produtiva do país. As madeiras nobres provenientes de espécies exóticas revelam-se uma opção promissora, considerando que o futuro está alicerçado em práticas sustentáveis. Neste cenário, o extrativismo da flora nativa torna-se cada vez mais ineficiente diante das discussões acerca da importância da conservação e preservação no processo produtivo (Ciriello et al., 2014).

O mogno-africano (Khaya senegalensis A. Juss) é uma espécie da família Meliaceae. Apresenta distribuição natural na África do Sul com ocorrência principal nos países do Senegal, Sudão do Sul, e as regiões do norte dos Camarões e Uganda (Perez et al., 2016). Possui caule retilíneo, alcançando até 35 metros de altura em solos férteis. A madeira tem a coloração escura, dura, pesada e durável, sendo utilizada, principalmente, na laminação, movelaria, construção naval, lâminas decorativas, instrumentos musicais e construções de interiores (Pinheiro et al., 2011 e Silva et al., 2016). A coloração do cerne e a aparência atraente a torna uma das melhores madeiras para móveis (Joker e Gaméné, 2003).

No Brasil, o mogno-africano é destaque dentre as espécies madeireiras exóticas por apresentar bom desenvolvimento em locais com predominância de clima tropical úmido, além de se adaptar bem a regiões de clima subtropical (Casaroli et al., 2018). Outro fator de incentivo aos reflorestamentos ocorre devido a proibição da exploração do mogno nativo (Decreto no 4.593, de 2003) e da resistência do mogno-africano ao ataque da Hypsipyla grandella Zeller, vulgarmente apresentada como broca do ponteiro, ocasionando danos aos brotos terminais, o que prejudica tanto o desenvolvimento da espécie quanto a qualidade da madeira produzida (França, 2015).

Ao considerar que o fósforo $(\mathrm{P})$ é uma fonte esgotável, com utilização ampla na agricultura brasileira e o predomínio de solos classificados como latossolos, o manejo adequado é vital para a manutenção das reservas químicas e para a viabilidade econômica de projetos; neste contexto a utilização de fontes solúveis além de eficiente é também vantajosa pela disponibilidade instantânea desse nutriente (Cabral et al., 2016). Além da carência generalizada de $\mathrm{P}$ nos solos brasileiros, $\mathrm{O}$ elemento apresenta forte interação com o solo (fixação), o que reduz a eficiência da adubação fosfatada (Faquin, 2005).

O P é composto vital em processos e estruturas que propiciam o desenvolvimento as plantas, desta forma sua ausência pode acarretar menor crescimento da planta, uma vez que é fundamental na produção de energia metabólica (Taiz e Zeiger, 2013). Os sintomas de deficiência de $\mathrm{P}$ não são tão marcantes como para outros macronutrientes, evidenciando um retardamento no desenvolvimento com coloração verde escura a arroxeadas nas folhas mais velhas (Araújo e Machado, 2006). Para atingir o máximo desenvolvimento, faz-se necessário o conhecimento das exigências nutricionais das espécies florestais, para, assim, garantir o fornecimento adequado dos nutrientes (Souza et al., 2010).

Em virtude da dinâmica do $\mathrm{P}$ nos solos mais intemperizados, a baixa disponibilidade para as plantas tem sido apontada como causa do inadequado desenvolvimento da maioria das culturas das regiões tropicais (Resende et al., 1999). Desta forma, o uso de fertilizantes fosfatados adicionados ao solo, para melhoria na fase inicial das plantas, é fato comprovado, sendo o rendimento máximo do vegetal obtido pela escolha da dose, fonte e época exata a ser utilizada.

Poucos são os estudos envolvendo oferta do $\mathrm{P}$ às espécies do gênero Khaya spp., porém são rotineiramente observadas respostas da necessidade de uma aplicação eficiente. Visto o potencial da espécie e a escassa existência de pesquisas sobre o assunto, objetivou-se avaliar o desenvolvimento inicial de plantas mogno-africano, adubadas com $\mathrm{P}$.

\section{Material e Métodos}

Caracterização do estudo

$\mathrm{O}$ experimento foi conduzido em casa de vegetação, na área experimental da Universidade Estadual de Goiás, Campus Ipameri (coordenadas geográficas: $17^{\circ} 43^{\prime} 19^{\prime}$ latitude S e $48^{\circ} 09^{\prime} 35^{\prime}$ " longitude $\mathrm{W}$; e altitude de $764 \mathrm{~m}$ ). As temperaturas de dentro da casa de vegetação foram da ordem de $11^{\circ} \mathrm{C}$ (mínima) e $43^{\circ} \mathrm{C}$ (máxima) e média de $27^{\circ} \mathrm{C}$.

\section{Delineamento experimental e tratamentos}

$\mathrm{O}$ delineamento experimental utilizado foi o inteiramente casualizado, com cinco tratamentos e seis repetições. Os tratamentos constituíram-se de cinco doses de P: 0, 50, 100, 150 e $200 \mathrm{mg} \mathrm{dm}^{-3}$, sendo a fonte de adubação utilizada o superfosfato triplo.

\section{Substrato, mudas, recipiente e as doses}

O substrato utilizado foi um solo agrícola classificado em Latossolo Vermelho-Amarelo distrófico (Embrapa, 2018), coletado na camada subsuperficial $(0,20$ a $0,40 \quad \mathrm{~m}) . \quad \mathrm{Na}$ análise granulométrica e química, o substrato apresentou os seguintes valores iniciais: $300,80,0$ e $620,0 \mathrm{mg} \mathrm{dm}^{-}$ ${ }^{3}$ de argila, silte e areia, $\mathrm{pH}\left(\mathrm{CaCl}_{2}\right)=5,1 ; \mathrm{H}+\mathrm{Al}=$ $2,2 \mathrm{cmol}_{\mathrm{c}} \mathrm{dm}^{-3} ; \mathrm{Ca}=0,8 \mathrm{cmol}_{\mathrm{c}} \mathrm{dm}^{-3} ; \mathrm{Mg}=0,3 \mathrm{cmol}_{\mathrm{C}}$ $\mathrm{dm}^{-3} ; \mathrm{P}($ Mehlich $)=1,2 \mathrm{mg} \mathrm{dm}^{-3} ; \mathrm{K}=0,04 \mathrm{cmol}_{\mathrm{c}} \mathrm{dm}^{-}$ 3; Matéria orgânica $=9,0 \mathrm{~g} \mathrm{dm}^{-3} ; \mathrm{CTC}=3,36 \mathrm{cmol}_{\mathrm{c}}$ $\mathrm{dm}^{-3} ; \mathrm{V} \%=34,57 ; \mathrm{Cu}=1,9 \mathrm{mg} \mathrm{dm}^{-3}, \mathrm{Fe}=43,9 \mathrm{mg}$ 
$\mathrm{dm}^{-3}, \mathrm{Mn}=3,4 \mathrm{mg} \mathrm{dm}^{-3}, \mathrm{Zn}=0,2 \mathrm{mg} \mathrm{dm}^{-3}, \mathrm{~B}=0,19$ $\mathrm{mg} \mathrm{dm}{ }^{-3}$, respectivamente.

A espécie utilizada foi a $K$. senegalensis A. Juss, cujas mudas foram produzidas a partir de sementes importadas do Continente Africano, em tubetes com substrato comercial e capacidade de 53 $\mathrm{cm}^{3}$, altura média de $15 \mathrm{~cm}$, diâmetro do coleto em média de $8 \mathrm{~mm}$, onde permaneceram até o momento de serem transplantadas para os vasos. Nesse período, não receberam nenhuma adubação.

Em função da análise granulométrica e química do solo utilizado, todas as amostras de solos dos tratamentos receberam calcário, $0,52 \mathrm{~g} \mathrm{dm}^{-3}$, para elevar a saturação por bases do solo para $60 \%$, por um período de 30 dias. Após 20 dias de incubação, procedeu-se a adubação com nitrogênio $\left(80 \mathrm{mg} \mathrm{dm}^{-3}\right)$, potássio $\left(80 \mathrm{mg} \mathrm{dm}^{-3}\right)$ e dos micronutrientes: manganês $\left(1,5 \mathrm{mg} \mathrm{dm}^{-3}\right)$, boro $(0,5$ $\left.\mathrm{mg} \mathrm{dm}{ }^{-3}\right)$, zinco $\left(5 \mathrm{mg} \mathrm{dm}^{-3}\right)$, cobre $\left(0,5 \mathrm{mg} \mathrm{dm}^{-3}\right) \mathrm{e}$ molibdênio $\left(0,1 \mathrm{mg} \mathrm{dm}^{-3}\right)$. As fontes utilizadas para calagem e adubação foram: calcário dolomítico PRNT 92, ureia, cloreto de potássio, sulfato de manganês, ácido bórico, sulfato de zinco, sulfato de cobre e molibdato de sódio, respectivamente. As doses dos nutrientes estabelecidos foram aplicadas via solução individualmente em cada vaso no momento do transplantio.

As mudas foram transplantadas para os vasos de polietileno preto opaco com perfurações no fundo, preenchidos com $7 \mathrm{dm}^{3}$ de solo, aos 120 dias de idade. A umidade do solo foi mantida durante todo o período experimental em, aproximadamente, $60 \%$ da capacidade máxima de retenção de água do solo. O volume de água evapotranspirado foi reposto diariamente, por meio de pesagem dos vasos.

\section{Análises e Características Avaliadas}

Após 180 dias do transplantio, as variáveis de crescimento foram aferidas, por meio da medição da altura de plantas, desde o colo até o ápice das plantas, com o auxílio de régua graduada, diâmetro do coleto, utilizando-se de um paquímetro digital e contagem do número de folíolos. Em seguida as plantas foram separadas em folhas caule, e raízes para a determinação de matéria seca. Realizou-se lavagem das partes das plantas com água destilada e, posteriormente, as mesmas foram colocadas em estufa de circulação forçada de ar por 72 horas, na temperatura de $70{ }^{\circ} \mathrm{C}$, até a obtenção de massa constante. Depois de secas, foram pesadas em balança analítica com precisão de $0,01 \mathrm{~g}$ para determinação da matéria seca de folhas, caule e raiz, e, pelo somatório das três, calculou-se a matéria seca total.

Após a determinação da matéria seca, foi realizada a moagem do material em moinho de aço inoxidável do tipo Willey, com peneira de 20 Mesh, procedendo a análise dos teores de $\mathrm{P}$ nas folhas.
Para determinação do teor de $\mathrm{P}$ no solo, no final do experimento, amostras de solos contidas nos vasos foram analisadas por meio de solução extratora de Mehlich. E para determinação dos teores de $\mathrm{P}$ nas folhas, utilizou-se o método de espectrofotometria com azul-de-molibdênio (Silva, 2009).

\section{Análise estatística dos resultados}

Os dados, após a verificação de atendimento dos pressupostos de homogeneidade de variâncias e de normalidade, foram submetidos à análise de variância e de regressão, $\operatorname{com} \alpha=0,05$, utilizando o software SISVAR 5.4 (Ferreira, 2011).

\section{Resultados e discussão}

A aplicação das doses de $\mathrm{P}$ influenciou $\mathrm{o}$ comportamento de todas as variáveis analisadas. As variáveis: altura, diâmetro do colo, número de folíolos, matéria seca de folhas, caule, raízes e total ajustaram-se ao modelo quadrático. Enquanto que o teor de $\mathrm{P}$ foliar e o teor de $\mathrm{P}$ no solo ajustaram-se ao modelo linear. É importante destacar que o P participa de processos essenciais ao desenvolvimento da planta, como a respiração e fotossíntese, sendo fundamental na transferência de energia da célula (Taiz; Zeiger, 2013). Por isto, foi verificado influencia positiva no crescimento das plantas quando foi fornecido $\mathrm{P}$ em doses adequadas. É importante salientar também que o excesso de $\mathrm{P}$ afetou negativamente o crescimento das plantas.

Para altura, o ponto de máxima curvatura foi observado na dose estimada de $131 \mathrm{mg} \mathrm{dm}^{-3}$, correspondendo a $67,5 \mathrm{~cm}_{\text {planta }}{ }^{-1}$, valor este, 98,3 $\%$ superior ás plantas cultivadas na dose $0 \mathrm{mg} \mathrm{dm}^{-3}$. $\mathrm{Na}$ dose máxima (200 $\mathrm{mg} \mathrm{dm}^{-3}$ ), também foi verificado que as plantas tiveram um decréscimo no crescimento em altura (Figura 1A).

A redução de $\mathrm{P}$ promoveu a restrição do crescimento em altura das plantas de mognoafricano. Os reflexos da aplicação de $\mathrm{P}$ nos incrementos de biomassa aludem a extrema necessidade da cultura ao nutriente nas fases iniciais. Em estudo com solução nutritiva também com $K$. senegalensis, Smiderle et al. (2018) observaram que o $\mathrm{P}$ juntamente ao $\mathrm{N}$ foram os nutrientes que mais limitaram o crescimento das mudas. Cardoso et al. (2015) também observaram que o fornecimento de níveis crescentes de $\mathrm{P}$ afetou de forma positiva $\mathrm{e}$ quadrática o crescimento das plantas de mognobrasileiro (Swietenia macrophylla) em altura. Respostas semelhantes são verificadas para o mogno brasileiro, altamente responsivo as doses de $\mathrm{P}$ tanto em níveis moderados (50 a $100 \mathrm{mg} \mathrm{dm}^{-3}$ ) (Resende et al., 1999) quanto para maiores doses (150 a 300 $\mathrm{mg} \mathrm{dm}^{-3}$ ) (Santos et al., 2008; Souza et al., 2010). 


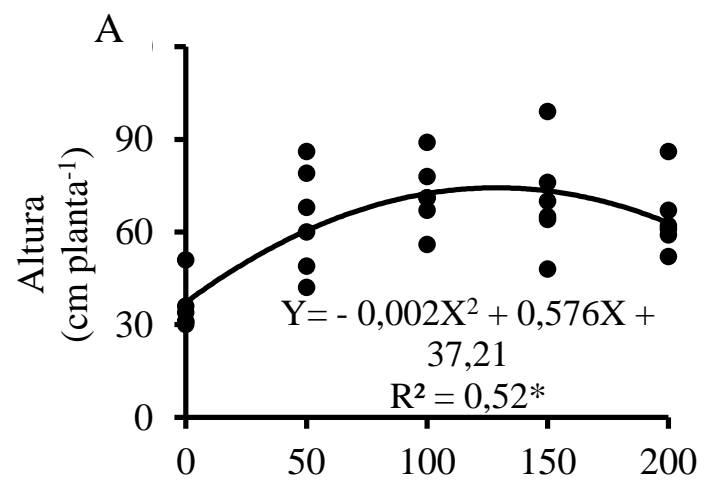

Doses de $\mathrm{P}\left(\mathrm{mg} \mathrm{dm}^{-3}\right)$
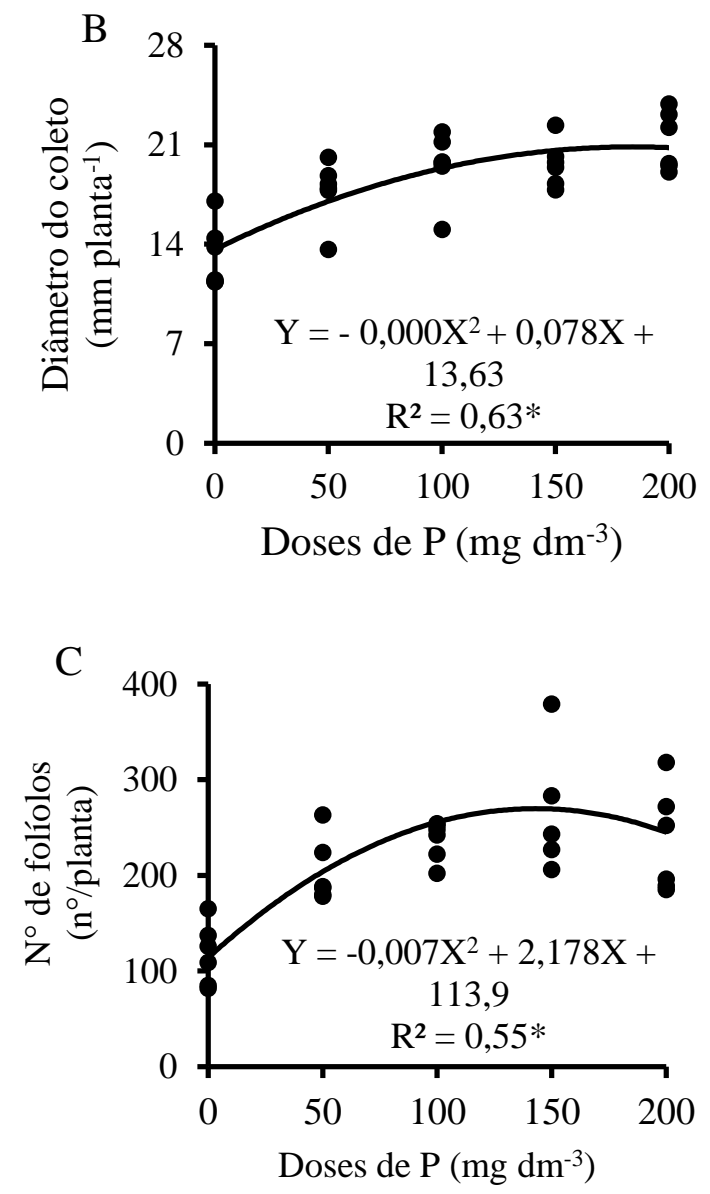

Figura 1. Funções de regressão para altura das plantas (A), diâmetro do coleto (B) e número de folíolos (C) de plantas de mogno-africano adubadas com $\mathrm{P}$ aos 180 dias após transplante. * significativo à $5 \%$ de probabilidade.

Também Vasconcelos et al. (2017) obtiveram o maior crescimento em altura nas plantas de mognoafricano ( $K$. senegalensis) quando foram cultivadas na dose $240 \mathrm{mg} \mathrm{dm}^{-3}$. Já Araujo et al. (2020) em estudo com outra espécie de mogno-africano (Khaya ivorensis), observaram que as doses que promoveram o máximo crescimento em altura foi a dose $200 \mathrm{mg} \mathrm{dm}^{-3}$ de P. Estes resultados refletem na importante função que $\mathrm{o} \quad \mathrm{P}$ desempenha no metabolismo das espécies do mesmo gênero e família do mogno-africano, sendo bastante responsiva a adubação fosfatada.

A exigência do mogno-africano ao $\mathrm{P}$ refletiu no crescimento progressivo aos níveis ofertados, promovendo um incremento de $110 \%$ no diâmetro das plantas. Foi possível observar o máximo crescimento em diâmetro das plantas $(19,2 \mathrm{~mm}$ planta $^{-1}$ ) encontrado na dose estimada de $196 \mathrm{mg} \mathrm{dm}^{-}$ 3 (Figura 1B). Tal resposta é benéfica ao desenvolvimento de espécies voltadas ao cultivo comercial em razão do incremento de biomassa, isso se deve ao reflexo da melhoria da disponibilidade e eficiência de extração de $\mathrm{P}$ do solo.

Dessa forma, a sobrevivência das mudas inseridas em campo pode estar vinculada ao diâmetro das mesmas, podendo proporcionar melhor crescimento e formação de raízes. Ainda, Cardoso et al. (2015) verificaram respostas de crescimento em diâmetro do colo em plantas de mogno-brasileiro $(S$. macrophylla), cultivado em um Latossolo Amarelo distrófico típico em casa de vegetação, entretanto o maior incremento alcançado foi na dose de $22 \mathrm{mg}$ $\mathrm{dm}^{-3}$ de $\mathrm{P}$, em virtude de sua classificação ecofisiológica (espécie climácica). Estudando a mesma espécie Santos et al. (2008) verificaram que o efeito da adubação fosfatada promoveu um efeito linear no incremento do diâmetro do colo da planta, onde a dose ideal de $\mathrm{P}$ foi de $200 \mathrm{~kg} \mathrm{ha}^{-1}$; já em eucalipto, Rocha et al. (2013) verificaram também resposta quadrática. Costa Filho (2013), determinou que as melhores respostas estão na faixa de 81 a 120 $\mathrm{mg} \mathrm{kg}{ }^{-1}$ de P. Garcia e Souza (2015) estudando Schizolobium parahyba verificaram que as mudas tiveram maior taxa de crescimento com aplicação de $800 \mathrm{mg} \mathrm{dm}^{-3}$.

Para número de folíolos, as plantas que não receberam a adubação de $\mathrm{P}$ apresentaram baixo número de folíolos, quando comparadas aos que receberam. A ausência de $\mathrm{P}$ comprometeu $\mathrm{o}$ desenvolvimento, evidenciando a importância do P na fase inicial das plantas de mogno-africano. A maior quantidade de folíolos (243 folíolos planta ${ }^{-1}$ ) ocorreu com a aplicação da dose estimada de $143 \mathrm{mg}$ $\mathrm{dm}^{-3}$ (Figura 1C). Comparando a dose ideal e o controle, observou-se aumento de $125 \%$ na quantidade de folíolos produzidos. Esse fator pode ter promovido efeito direto na produção de fitomassa total da planta, uma vez que tal restrição pode ter prejudicado a fotossíntese, especificamente a produção de fotoassimilados (Taiz e Zeiger, 2013).

As doses crescentes de $\mathrm{P}$ promoveram o aumento do número de folíolos, provavelmente por fomentar processos fotossintéticos, bem como a biossíntese de folhas, mas sua alta disponibilidade estaria contribuindo para a promoção do processo. Tal elemento desempenha funções estruturais, participando de compostos orgânicos vitais ao desenvolvimento da planta, destacando o ATP (Prado, 2008). Em estudos com adubação fosfatada 
em goiabeira, sabiá e gonçalo-alves, Corrêa et al. (2003) e Costa Filho (2013), verificaram que houve resposta positiva ao aumento das doses de $\mathrm{P}$ na produção de folhas, com respostas quadráticas em função das doses aplicadas, constatando o efeito nocivo do nutriente nas concentrações máximas testadas.

A matéria seca de raiz (MSR) apresentou efeito estatístico significativo nas doses testadas com efeito quadrático (Figura 2A). As doses crescentes de $\mathrm{P}$ promoveram um aumento na MSR até a dose de
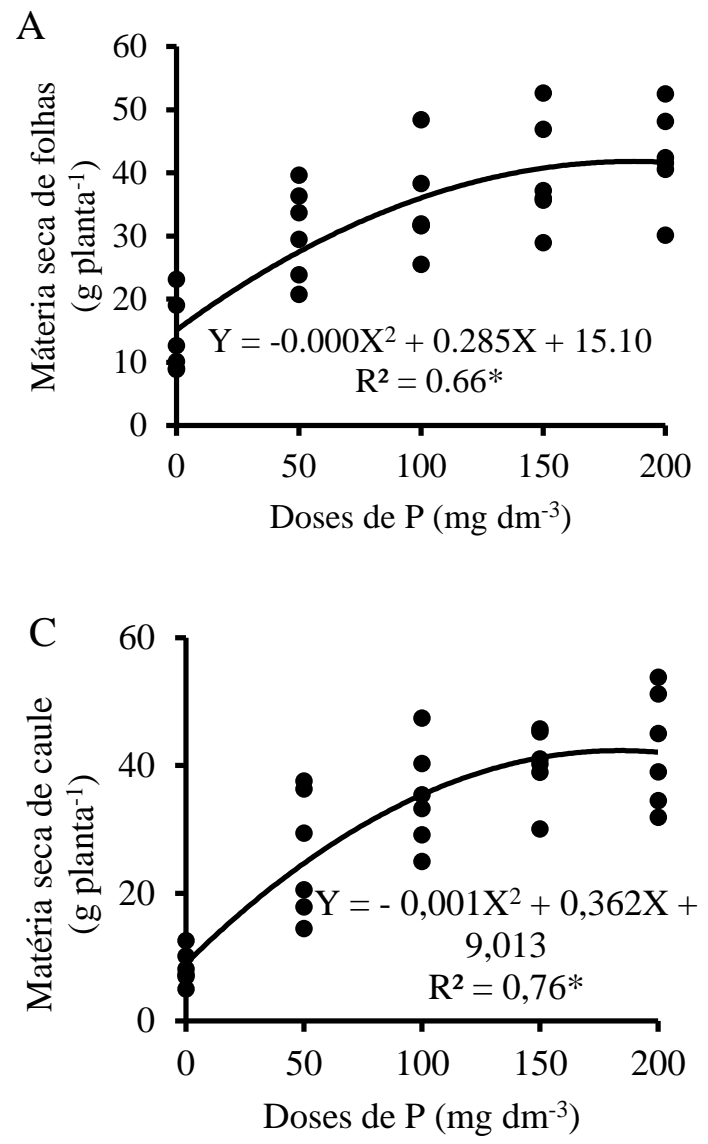

$168 \mathrm{mg} \mathrm{dm}^{-3}$, resultando em um peso máximo estimado de $53 \mathrm{~g}$ planta $^{-1}$. Os níveis de $\mathrm{P}$ ofertados foram tão expressivos que o incremento de matéria seca de raiz chegou a $279,5 \%$ em comparação como controle. Tais observações reforçam a necessidade de $\mathrm{P}$ nas fases iniciais de desenvolvimento da espécie. Com a produção de raízes as plantas terão maiores condições de interceptação radicular para absorção de P, de água e demais nutrientes, garantido a viabilidade econômica e ambiental da implantação de povoamentos comerciais.
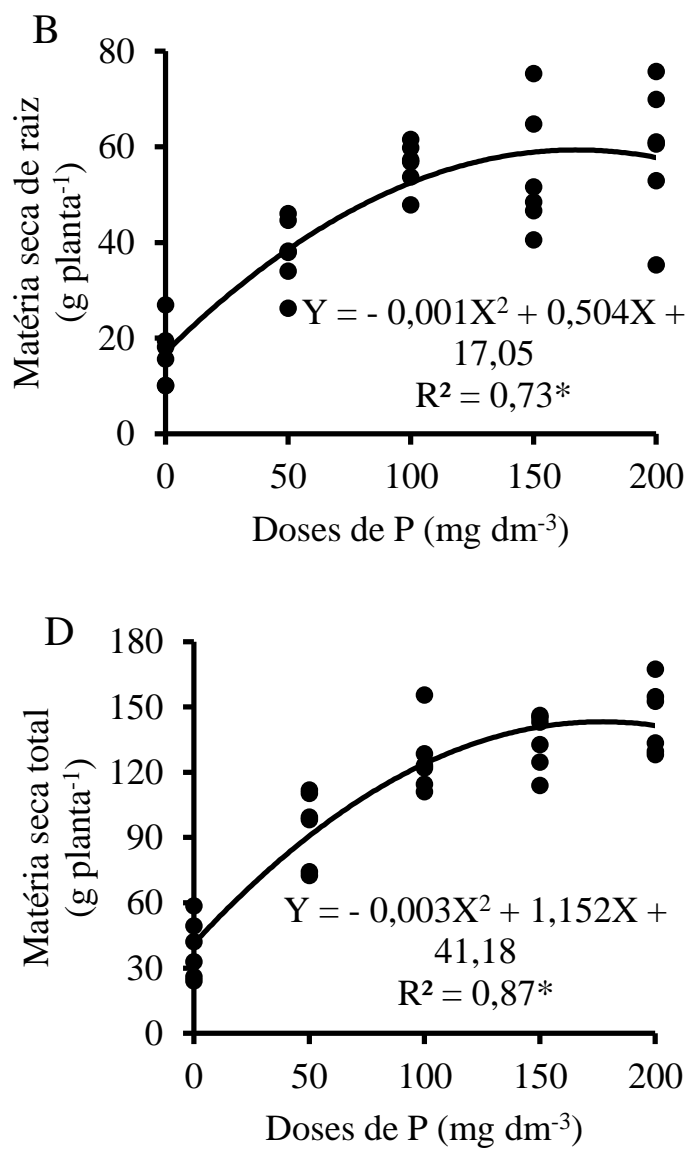

Figura 2. Funções de regressão para matéria seca de raiz (A), matéria seca de folhas (B), matéria seca de caule (C) e matéria seca total (D) de plantas de mogno-africano adubadas com $\mathrm{P}$ aos 180 dias após transplante. * significativo à $5 \%$ de probabilidade.

Em análise ao desenvolvimento inicial de mogno-africano (Khaya ivorensis), Ros et al. (2019), verificaram a exigência da espécie em $\mathrm{P}$, obtendo maior produção de biomassa quando foi realizado a adubação fosfatada na dose máxima de $200 \mathrm{~kg} \mathrm{ha}^{-1}$ de $\mathrm{P}_{2} \mathrm{O}_{5}$. Dechassa et al. (2003) e Marschner, (2012) descrevem que a taxa de crescimento da raiz depende do fornecimento de $\mathrm{P}$, importante na transferência de energia da célula, na respiração, na fotossíntese, com reflexos negativos quando indisponível, reduzindo o acúmulo de biomassa, afetando o crescimento radicular. Dessa forma, é possível verificar que o mogno-africano é altamente sensível a presença de
$\mathrm{P}$, notando que sua indisponibilidade pode retardar o desenvolvimento da espécie.

Ao analisar o efeito das doses de $\mathrm{P}$ utilizadas, foi possível constatar o efeito decrescente a partir da dose ideal para matéria seca de folhas, caule e raiz. Essa redução pode estar vinculada a variedade de processos metabólicos que o elemento participa, onde doses reduzidas de $\mathrm{P}$ promovem um prejuízo no desenvolvimento de mudas, assim como doses elevadas. Tal efeito nocivo das doses elevadas do macronutriente ocorre em razão de algumas espécies não conseguirem evitar $\mathrm{o}$ alto consumo de $\mathrm{P}$, ocasionando a toxidade do elemento (Furtini Neto et 
al. 1996; Rocha et al. 2013), situação observada no presente estudo.

Para matéria seca de folhas e caule verificouse também a influência das doses de P. As maiores produções de matéria seca de folhas e caule foram nas doses de $178 \mathrm{mg} \mathrm{dm}^{-3}$ (36,5 $\left.\mathrm{g} \mathrm{planta}^{-1}\right)$ e $181 \mathrm{mg}$ $\mathrm{dm}^{-3}(37,7 \mathrm{~g})$, respectivamente (Figura $2 \mathrm{~B}$ e C). Os efeitos mais expressivos estão próximas a faixa de $150 \mathrm{mg} \mathrm{dm}^{-3}$ e verifica-se resposta de decréscimo quando submetidas a dose de $200 \mathrm{mg} \mathrm{dm}^{-3}$, reduzindo a produção da biomassa seca das plantas.

Assim como verificado para o mognoafricano, o pinhão-manso foi altamente responsivo as doses crescentes de $\mathrm{P}$ para a produção de matéria seca de folhas, segundo Freiberger et al. (2014). Santos et al. (2008) verificaram que nas espécies pioneiras estudadas há um potencial maior de absorção de $\mathrm{P}$ em resposta as doses de $\mathrm{P}$ aplicadas, observando um padrão quanto ao acúmulo desse nutriente na parte aérea, fato também observado neste estudo. Já em eucalipto é verificado uma resposta linear com o aumento das doses de $\mathrm{P}$ aplicadas (Rocha et al., 2013).

Analisando a exigência do eucalipto a doses de P, Rocha et al. (2013) verificaram o efeito quadrático das doses sobre o incremento de massa seca do caule. Gonçalves et al. (1992) ressaltaram que as taxas de crescimento e absorção são reflexos de um sistema radicular bem desenvolvido, em decorrência da presença de raízes finas assim como o aumento do volume de solo explorado pelas raízes, facilitando a absorção nutricional. Isso aumenta o volume de solo explorado pelas raízes, facilitando a absorção de $\mathrm{P}$, principalmente em solos argilosos altamente intemperizados. Portanto, o maior crescimento de raízes das plantas submetidas a doses maiores de $\mathrm{P}$ refletem no maior crescimento $\mathrm{e}$ desenvolvimento das plantas de mogno, ofertando maiores níveis de absorção nutricional e incremento de matéria seca.

As respostas observadas para matéria seca total mostram diferenças estatísticas entre as doses testadas, podendo constatar que as doses fornecidas incentivaram a produção de matéria seca total (Figura 2D). Analisando os componentes em conjunto (raiz, caule e folhas) verifica-se que a dose que promoveu maior incremento de matéria seca total foi de $175 \mathrm{mg} \mathrm{dm}^{-3}$, resultando num peso máximo total de $128 \mathrm{~g} \mathrm{planta}^{-1}$. $\mathrm{O}$ efeito da análise de regressão foi quadrática, indicando que após essa dose, verifica-se o efeito nocivo no incremento de matéria seca.

O incremento na biomassa total, foi constatado por Silva et al. (2009) verificando uma redução de cerca de $68 \%$ na produção de massa de matéria seca total com mudas de pinhão-manso
(Jatropha curcas) submetidas a omissão de P. Ainda nesse estudo, a dose que promoveu a melhoria nos aspectos analisados está na faixa dos $57 \mathrm{mg} \mathrm{dm}^{-3}$, dessa forma, verifica-se que a falta de $\mathrm{P}$ ou doses baixas do macronutriente retarda e prejudica o desenvolvimento de mudas. Dose próxima foi indicada por Souza et al. (2011), recomendando cerca de $55 \mathrm{mg} \mathrm{dm}^{-3}$ de P para o desenvolvimento inicial do pinhão-manso. $\mathrm{O}$ eucalipto também mostrou respostas quadráticas quando submetido a doses de P (Rocha et al. 2013). Estudando o comportamento espécies de crescimento rápido $\mathrm{e}$ lento submetidas a doses de P, Santos et al. (2008) verificaram que as espécies pioneiras (aroeira, aroeirinha e sesbânia) foram mais responsivas do que as espécies climácicas (guanandi e óleobalsamo). Efeitos quadráticos de incremento de biomassa total também foram verificados para Eucalyptus dunnii com dose ideal de $256 \mathrm{mg} \mathrm{dm}^{-3}$ (Stahl, 2013). Esse último descreve que as respostas observadas em doses altas de $\mathrm{P}$, podem ser explicadas pela condução experimental em vasos, permitindo uma melhor relação entre raízes e solo, permitindo melhor exploração do sistema radicular.

Já em altas concentrações, o P mostra-se prejudicial, já que diminui a disponibilidade de zinco para a planta, pois o zinco se liga ao cátion acompanhante do P (Corrêa et al., 2002). E nestas condições, as plantas apresentam pequeno desenvolvimento, como verificado nas plantas submetidas à dose máxima $\left(200 \mathrm{mg} \mathrm{dm}^{-3}\right)$.

$\mathrm{O}$ teor de $\mathrm{P}$ presente nas folhas apresentou efeito às doses crescentes de $\mathrm{P}$ aplicadas, apresentando um comportamento linear. Seus teores quando submetidas a omissão de $\mathrm{P}\left(0 \mathrm{mg} \mathrm{dm}^{-3}\right)$ e a dose $50 \mathrm{mg} \mathrm{dm}^{-3}$ foram, de maneira bastante significativa, mais baixos comparado aos demais tratamentos. A máxima dose $\left(200 \mathrm{mg} \mathrm{dm}^{-3}\right)$ apresentou maiores teores de $\mathrm{P}$ nas folhas, entretanto a dose que proporcionou maior desenvolvimento para planta foi observado mediante a aplicação das doses de $\mathrm{P}$ de 100 a $150 \mathrm{mg} \mathrm{dm}^{-3}$ (Figura 3A).

$\mathrm{O}$ teor de $\mathrm{P}$ disponível no solo também se verificou aumento na concentração conforme se aumentaram as doses de $\mathrm{P}$, ajustando-se a um comportamento linear. A dose máxima $200 \mathrm{mg} \mathrm{dm}^{-3}$ apresentou maiores valores de $\mathrm{P}$ disponível, em média $6 \mathrm{mg} \mathrm{dm}^{-3}$ (Figura 3B). Esse baixo valor pode ser explicado pela forte interação que o $\mathrm{P}$ possui com o solo (fixação), tornando-se de forma não disponível para as plantas (Tavares et al., 2016). Mesmo comportamento também foi observado por Ros et al. (2019), onde os teores de P no solo foram maiores quando foi aplicado maiores doses no cultivo de mogno-africano. 


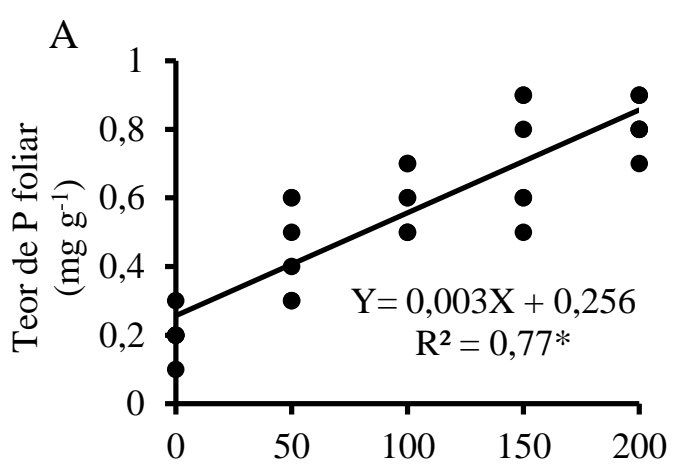

Doses de $\mathrm{P}\left(\mathrm{mg} \mathrm{dm}^{-3}\right)$

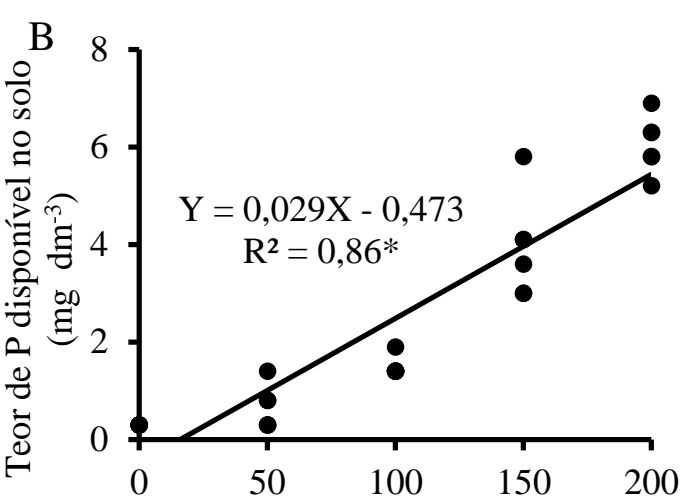

Doses de $\mathrm{P}\left(\mathrm{mg} \mathrm{dm}^{-3}\right)$

Figura 3. Funções de regressão para teor de $\mathrm{P}$ foliar (A) e teor de $\mathrm{P}$ disponível no solo (B) de plantas de mognoafricano adubadas com $\mathrm{P}$ aos 180 dias após transplante. * significativo à $5 \%$ de probabilidade $\mathrm{e}^{* *}$ significativo à $1 \%$ de probabilidade.

\section{Conclusões}

A adição de $\mathrm{P}$ no solo promoveu o incremento na matéria seca de folha, caule, raiz e total e no crescimento em altura, diâmetro e número de folíolos de plantas de mogno-africano cultivadas em casa de vegetação.

Recomenda-se a aplicação de $175 \mathrm{mg} \mathrm{dm}^{-3}$ de $\mathrm{P}$ para o maior desenvolvimento inicial de mognoafricano em solos com baixa teor do nutriente.

Com o aumento de $\mathrm{P}$ aplicado no solo, houve aumento no teor de $\mathrm{P}$ nas folhas e de $\mathrm{P}$ disponível no solo.

\section{Referências}

Araújo AP, Machado CTT, Fósforo. In: Fernandes, M. S. (2016) Nutrição mineral de plantas. $1^{\mathrm{a}}$ ed. Viçosa, Sociedade Brasileira de Ciência do Solo. 432p.

Araújo MS, Cunha SD, Gatto A, Hodecker BER, Pelá A (2020) Desenvolvimento inicial e nutrição de mudas de mogno-africano em resposta à adubação nitrogenada e fosfatada. Scientia forestalis, 48(125): 1-12. doi.org/10.18671/scifor.v48n125.14

Cabral CEA, Cabral LS, Silva EMB, Carvalho KSC, Kroth BE, Cabral CHA (2016) Resposta da Brachiaria brizantha $\mathrm{cv}$. Marandu a fertilizantes nitrogenados associados ao fosfato natural reativo. Comunicata Scientiae, 7(1): 66-72. doi:10.14295/CS.v7i1.964

Casaroli D, Rosa FO, Alves Júnior J, Evangelista AWP, Brito BV, Pena DS (2018). Aptidão edafoclimática para o mogno-africano no Brasil. Ciência Florestal, 28(1): 357-368. dx.doi.org/10.5902/1980509831606

Cardoso AAS, Santos JZL, Tucci CAF, Farias EP, Moura RPM (2015) Influência da acidez e do teor de fósforo do solo no crescimento inicial do mogno. Pesquisa Florestal Brasileira, 35(81):1-10. doi:10.4336/2015.pfb.35.81.667

Ciriello V, Guerrini IA, Backes C (2014) Doses de nitrogênio no crescimento inicial e nutrição de plantas de guanandi. Cerne, 20(4):653-660. doi:10.1590/01047760201420041445

Corrêa FLO, Souza CAS, Carvalho JG, Mendonça V (2002) Fósforo e zinco no desenvolvimento de mudas de Aceroleira. Revista Brasileira de Fruticultura, 24(3):793-796.

Corrêa MCM, Corrêa MDM, Prado RDM, Natale W, Pereira L, Barbosa JC (2003) Resposta de Mudas de goiabeira a doses e modos de aplicação de fertilizante fosfatado. Revista Brasileira de Fruticultura, 25(1):164-169. doi:10.1590/S010029452003000100045

Costa Filho RT, Valeri SV, Cruz MCP (2013) Calagem e adubação fosfatada no crescimento de mudas de Mimosa caesalpinifolia Benth. em Latossolo vermelho-amarelo. Ciência Florestal, 23(1):89-98. doi:10.5902/198050988442

Dechassa NMK, Claassen N, Steingrobe B (2003) Phosphorus Efficiency of cabbage (Brassica oleraceae L. Var. Capitata), carrot (Daucus carota L.), and potato (Solanum Tuberosum L.). Plant and Soil, 250 (1):215-224.

Embrapa (2018) Sistema brasileiro de classificação de solos. $3^{\mathrm{a}}$ ed. Brasília, Embrapa Solos, 201p.

Faquin, V (2005) Nutrição mineral de plantas. $1^{\mathrm{a}} \mathrm{ed}$. Lavras, 183p.

Ferreira DF (2011) Sisvar: a computer statistical analysis system. Ciência e Agrotecnologia. 35 
(6):1039-1042.

doi:10.1590/S1413-

70542011000600001

França TSFA, Arantes MDC, Paes JB, Vidaurre GB, Oliveira JTS, Baraúna EEP (2015) Características anatômicas e propriedades físico-mecânicas das madeiras de duas espécies de mogno africano. Cerne, 21(4):633-640.

doi:10.1590/01047760201521041877

Freiberger MB, Guerrini IA, Castoldi G, Pivetta LG (2014) Adubação Fosfatada no crescimento inicial e na nutrição de mudas de pinhão-manso. Revista Brasileira de Ciência do Solo, 38(1):232-239. doi:10.1590/S0100-06832014000100023

Furtini Neto AE, Barros NF, Godoy MF, Novais RF (1996) Eficiência nutricional de mudas de Eucalyptus em relação a fósforo. Revista Árvore, 20(1):17-28.

Garcia EA, Souza JP (2015) Avaliação da qualidade de mudas de schizolobium parahyba em função de diferentes aplicações de adubo fosfatado. Tekhne $e$ Logos, 6(1):51-59.

Gonçalves JLM, Gonçalves JDM, Kageyama PY, Freixêdas VM, Gonçalves JC, Geres WDA (1992) Capacidade de absorção e eficiência nutricional de algumas espécies arbóreas tropicais. Revista do Instituto Florestal, 4(1):463-469.

Joker D, Gaméné S (2003) Khaya senegalensis (Desr.) A. Juss. $1^{\text {a }}$ ed. Humlebaek, Danida Forest Seed Centre, 203p.

Marschner P (2012) Mineral nutrition of higher plants. $3^{\mathrm{a}}$ ed. London: Academic Press, 655p.

Oliveira J, Oliveira JMF, Silva AJ, Schwengber DR, Duarte OR (1997) Resposta de mudas de angelimpedra (Dinizia excelsa Ducke) a nitrogênio e fósforo. Pesquisa Agropecuária Brasileira, 9(33):15031507.

Perez BAP, Valeri SEV, Cruz MCP, Vasconcelos RT (2016) Potassium doses for African mahogany plants growth under two hydric conditions. African Journal of Agricultural Research, 11(22):19731979. doi:10.5897/AJAR2016.11026

Pinheiro AL, Couto L, Pinheiro DT, Brunetta JMFC (2011) Ecologia, silvicultura e tecnologia de utilização dos mognos-africanos (Khaya spp.). $1^{\mathrm{a}} \mathrm{ed}$. Viçosa, Sociedade Brasileira de Agrossilvicultura, $102 p$.

Prado RM (2008) Nutrição de plantas. $1^{\mathrm{a}}$ ed. São Paulo, Editora Unesp, 407p.
Resende AV, Urtini Neto AE, Muniz JA, Curi N, Faquin, V (1999) Crescimento inicial de espécies florestais de diferentes grupos sucessionais em resposta a doses de fósforo. Pesquisa Agropecuária Brasileira, 34(11):2071-2081.

Rocha JHT, Pietro MR, Borelli K, Backes C, Neves MB (2013) Produção e desenvolvimento de mudas de eucalipto em função de doses de fósforo. Cerne, 19(4):535-543. doi:10.1590/S010477602013000400002

Ros CO, Sestari G, Jaeger G, Oliveira EH, Weber ML, Silva RF, Torchelsen M. (2019) Efeito da calagem e da adubação fosfatada no crescimento inicial e na nutrição das plantas de Khaya ivorensis. Scientia Forestalis, (47)123:430-439. doi.org/10.18671/scifor.v47n123.05

Santos RA, Tucci CAF, Hara FAS, Silva WG (2008) Adubação fosfatada para a produção de mudas de mogno (Swietenia macrophylla King). Acta Amazônica, 38(3):453-458. doi:10.1590/S004459672008000300009

Santos JZL, Resende AV, Furtini Neto AE, Corte EF (2008) Crescimento, acúmulo de fósforo e frações fosfatadas em mudas de sete espécies arbóreas nativas. Revista Árvore, 32(5):799-807. doi:10.1590/S0100-67622008000500003

Silva EB, Tanure LPT, Santos SR, Resende Júnior PS (2009) Sintomas visuais de deficiências nutricionais em pinhão-manso. Pesquisa Agropecuária Brasileira, 44(1):392-397. doi:10.1590/S0100-204X2009000400009.

Silva FC (2009) Análise química de tecido vegetal. In: Manual de Análises Químicas de Solo, Plantas e Fertilizantes. $2^{\mathrm{a}}$ ed. Brasília, Embrapa Informação Tecnológica, 193-204p.

Silva JGM, Vidaurre GB, Arantes MDC, Batista DC, Soranso DR, Billo DF (2016) Qualidade da madeira de mogno africano para a produção de serrados. Scientia Forestalis, 44(109):181-190. doi:10.18671/scifor.v44n109.18

Smiderle OJ, Souza AG, Chagas EA, Alves MS, Fagundes PRO (2018) Parâmetros de crescimento e curva de absorção de nutrientes de mudas de mogno africano com e sem solução nutritiva. Revista Brasileira de Agropecuária Sustentável, 8(4):83-91. doi.org/10.21206/rbas.v8i4.3066

Souza CAS, Tucci CAF, Silva JF, Ribeiro WO (2010) Exigências nutricionais e crescimento de plantas de mogno (Swietenia macrophylla King.). Acta Amazonica, 40(3):515-522. doi:10.1590/S0044-59672010000300010 
Souza PT, Silva EB, Grazziotti PH, Fernandes LA (2011) NPK fertilization on initial growth of physic nut seedlings in Quartzarenic Neossol. Revista Brasileira de Ciência do Solo, 35(1):559-566. doi:10.1590/S0100-06832011000200025

Stahl J, Ernani PR, Gatiboni LC, Chaves DM, Neves CU (2013) Produção de massa seca e eficiência nutricional de clones de Eucalyptus dunni e Eucalyptus benthamii em função da adição de doses de fósforo ao solo. Ciência Florestal, 23(2):287-295. doi:10.5902/198050989275

Taiz L, Zeiger E. (2013) Fisiologia vegetal. $5^{\mathrm{a}}$ ed. Porto Alegre, Artmed, 954p.

Tavares SLR, Franco AA, Silva MR (2016) Resposta de Acacia mangium Willd a inoculações com rizóbio e micorriza em diferentes níveis de fósforo em solo de restinga degradado. Holos, 7(32):242-257. doi:10.15628/holos.2016.3932

Vasconcelos RT, Valeri SV, Cruz MCP, Barbosa JC, Barretto VCM (2017) Fertilização fosfatada na implantação de Khaya senegalensis A. Juss. Scientia Forestalis, 45(116):1-10. http://dx.doi.org/10.18671/scifor.v45n116.05 